variation is correlated with a certain death-rate, it must be the cause of it, and that it is not possible to distinguish between variations which are directly useful, and those which are only physiologically correlated with the useful. But it seems to me that this is like talking of hitting a noninative case with a stick. The variation is a magnitude in an organism, survival or death is a relation between the organism and its environment. It is the relation of the variation to life which alone can be said to be the cause of death or survival. The relation to the conditions of life is advantage, disadvantage, or neutrality in the struggle for existence. If I have stated the logic of the matter correctly, I venture to think that the apprehension of this principle is a necessary preliminary to any attempt to demonstrate empirically the occurrence of natural selection.

Prof. Weldon's chief contention was that by the statistical method, when the law of growth of the characters examined was known, a measure of the rate and direction of the evolution of an organism could be obtained. Such a measure would be afforded by the selective death-rate. But he has not yet demonstrated a selective death-rate in a single instance. And further, a measure of the rate and direction of evolution has nothing to do with the cause of the selective death-rate. If characters of no apparent utility are proved to be subject to selection, there still remains the question how the selection is brought about. Measures of the rate and direction of the wind do not tell us the cause of the wind. They may help us to discover the cause, and I have no doubt that Prof. Weldon's investigations are a valuable contribution to the investigation of evolution. But it is only when it has been shown that the degree of utility of a variation, or its correlation with useful variations determines its survival, that the occurrence of natural selection has been demonstrated.

September 19.

\section{Fossil Tridacnids in the Solomon Islands.}

Some months ago, on the voyage between New Guinea and Sydney, the small trading steamer on which I travelled called at a number of islands in the British Solomons, the first station at which we called being Rubiana, in the little-known island complex of New Georgia. Here I became acquainted with the heavy arm-rings worn by the natives, and obviously made from the shell of Tridacna or Hippopus. What was very surprising, however, was the information which I obtained from all quarters and from different localities, from blacks as well as from whites, that these arm-rings are not made from recent shells found on the reef, but from shells obtained far away in the interior, or, as they say, in the bush. At first sight, the arm-rings, above referred to, strongly remind one of those made from the recent Tridacna by the natives of the Sir Charles Hardy Island, which lies to the north of the Solomon Group; but while the former are solid rings more than half an inch in thickness, the latter are deeply grooved on the outer border.

This difference is shown in Figs. I and 2, which represent cross-sections through the arm-rings of the Solomon and Sir



FIG. x.

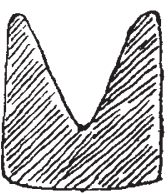

FIG. 2.
Charles Hardy islanders, respectively. But there are other differences, not so much of artistic as of economic importance. The grooved rings are much more readily obtained from the natives who make and wear them, than are the solid rings. The latter have a great value among the natives themselves, and when they are shot with a vein of reddish or reddish-yellow colour (derived no doubt from the hinge-line, which also gives their beauty to the nose-pieces of the New Guinea natives), they can only be mentioned with bated breath.

The reason why the Solomon Islanders prefer the ancient to the recent shells, lies possibly in the fact that, as a general rule, among the natives of the larger islands of the Pacific, the artists and artificers (apart from the making of canoes) are to be NO. I 405 , VOL. 54$]$ found among the bush-natives, rather than among those who live in proximity to the sea. The latter are traders:par excellencemen of the world who do their business in great waters. The former live in primitive innocence, are possessed of uncouth manners, and produce poets, magicians, medical men, and professional dancers, together with workers in wood and stone. To the last-mentioned members of the community, therefore, the Tridacnid shells, when they occur in the bush through elevation of a former coral reef, are ready conveniently to hand.

I have thought it worth while to draw the attention of naturalists to the above indication of the existence of upraised coral reefs in the Solomon Islands, which would be well worth an attentive examination, and, while in Sydney, Mr. R. Etheridge, jun., informed me that he knew of other instances in the Pacific of coral reefs having been raised to an elevation of over a thousand feet. ARTHUR WIILER.

Nouméa, New Caledonia, July i6.

\section{Visual Aid in the Oral Teaching of Deaf Mutes.}

Probably every one is acquainted with Køenig's manometric capsules and revolving mirrors, and it occurred to me that I might help a deaf mute to learn inflection in speaking by his imitating the curves produced by my voice in the mirrors. For this purpose I arranged two capsules with oblique membranes and small diameter side by side, one being higher than the other, so that two bands of flame half inch wide, and half inch apart, appeared in the revolving mirrors. The capsules were tuned alike, and furnished with tubes and conical mouthpieces ; through one of these I made the sound of a note, vowel, or syllable in various pitches, and my friend endeavoured to imitate through the other tube the curve in the flame band produced by my voice. As an experiment the results were quite satisfactory, for before an hour was over he could imitate a range of nearly an octave, and would tell me correctly, through watching the curves of flame, when the note he uttered was like mine. I am not interested in the oral teaching of the deaf, but having frequently to use Kœnig's invention, I think the principle might be made useful to oral teachers. My friend, upon whom I experimented, is said to have been well taught, his age about twenty years, but his voice (?) is a hoarse monotone. T. HAw KSLEY.

I I Primrose Hill Road, N.W.

\section{INTERNATIONAL METEOROLOGICAL CONFERENCE AT PARIS}

THIS Conference was held at the rooms of the Société d'Encouragement, in the Rue de Rennes, from September 17 to 23 . About forty members were present. M. Mascart was elected President, MM. de Bezold and Tacchini Vice-Presidents, and MM. Angot, Erk, and Scott Secretaries. The complete report of proceedings has not yet been printed. It was decided that Committees should be appointed to continue the investigation of several subjects, viz. :

I. Terrestrial Magnetism and Atmospheric Electricity ; Prof. Rücker (President)

II. Clouds ; Prof. Hildebrandsson (President).

III. Radiation and Insolation ; M. Violle (President).

IV. Aerostatics and Balloon Work; Prof. Hergesell (President).

On the motion of Mr. Symons, the International Meteorological Committee was reappointed with a few changes, rendered necessary by the respective resignations of Prof. Wild, Prof. Harrington, and Mr. Ellery. The President is Prof. Mascart, and the Secretary Mr. R. H. Scott.

\section{ARMAND HIPPOLYTE LOUIS FIZEAU.}

$\mathrm{BY}^{\mathrm{Y}}$ the death of $\mathrm{M}$. Fizeau physical science has lost one who will rank high among those who have contributed to the scientific distinction of the nineteenth century. Every student of optics knows M. Fizeau's beautiful experimental method of determining the velocity of light; but not so many are aware of the other re- 